\title{
Sports injuries in adults: overview of clinical examination and management
}

\author{
Janse van Rensburg DC, MMed(PhysMEd), MScSportsMedicine, MBChB \\ Section Sports Medicine, University of Pretoria \\ Nolte K, MA(HMS) \\ Institute for Sports Research, University of Pretoria \\ Correspondence to: Dr DC Janse van Rensburg, e-mail: vrensburg@sport.up.ac.za \\ Keywords: sports injuries; athletic injuries; musculoskeletal injuries; inflammation; overuse injuries; acute injuries; diagnosis; treatment; adults
}

\begin{abstract}
A wide variety of anatomical structures can be involved in a sports injury. To return to play as soon as possible is of utmost importance to an athlete, and in order to achieve this, a correct, all-inclusive diagnosis, a well-focused treatment plan, and a management plan that strives to offer protection are essential.

This article aims to give an overview of acute and overuse (chronic) sports injuries in adults, the approach to an accurate diagnosis and the management strategies that are available.

A literature review was conducted of scientific journals, text and internet material, including a Medline and PubMed search. Literature was selected for its in-depth data and well-researched information. Key search terms included "acute and overuse injuries", as well as "sports injuries diagnosis and management" to address current and relevant scientific data on the examination and management of sports injuries in adults.

The literature review indicated that sports injuries (both acute and overuse) are increasing in number due to the growing interest in physical activity and sport, as well as the enhanced intensity of training programmes. Adults are vulnerable to both types of sports injuries, and the age of occurrence of overuse injuries varies in competitive and non-competitive athletes. The importance of making an accurate diagnosis cannot be overemphasised. To assist the clinician in making an accurate diagnosis, a comprehensive history, physical examination and appropriate special investigations are mandatory. Familiarity with the demands of the athlete's sport may also prove useful. The approach to the management of acute and overuse injuries differs, with the emphasis in acute injuries being on treating the effect (torn, broken, displaced) and in chronic injuries on treating the cause (intrinsic or extrinsic). There have been numerous advances in the management of sports injuries, however further research is still warranted in this area. Follow-up articles will focus more in-depth on specifics with regard to clinical examination, special investigations and management options.
\end{abstract}

(P) Peer reviewed. (Submitted: 2010-07-16, Accepted: 2011-02-12). @ SAAFP

S Afr Fam Pract 2011;53(1):21-27

\section{Introduction}

It is clear that an increasing number of people (young and old) are becoming active to acquire the health benefits that exercise offers. ${ }^{1}$ Ironically, participation in any type of physical activity places the athlete in situations in which injury is likely to occur. ${ }^{2}$ In its broadest sense, the term "sports injury" refers to injuries that occur during sport or exercise. Virtually any part of the body can be injured and therefore one needs a structured approach to correctly diagnose and effectively manage sports injuries. ${ }^{2,3}$ This article will deal specifically with the diagnosis of sports injuries in adults, as well as the management of such injuries, concentrating on novel diagnostic and treatment options.

\section{Classification}

Sports injuries are caused by trauma of different degrees. They can be classified into acute and chronic injuries. Acute injuries occur from a single, well-defined incident and may follow contact or non-contact forces, such as a shoulder dislocation or ankle sprain. ${ }^{3}$ On the other hand, chronic injuries follow an accumulation of micro-trauma to bone, cartilage, ligaments, tendon and muscles. Patients can seldom identify an exact incident, or force that caused an overuse injury. ${ }^{4,5}$ According to Peterson and Renström (2001), these injuries are becoming increasingly common as both participation in sport in general and the intensity of training increases. The age of occurrence of overuse 
Table I: Presentation of acute and chronic injuries in various anatomical structures of the body (Adapted from Brukner et al, 2009) ${ }^{5}$

\begin{tabular}{|c|c|c|}
\hline Area & Acute injuries & Chronic injuries \\
\hline Joint & $\begin{array}{l}\text { Subluxation } \\
\text { Dislocation }\end{array}$ & $\begin{array}{l}\text { Osteoarthritis } \\
\text { Synovitis }\end{array}$ \\
\hline $\begin{array}{l}\text { Articular } \\
\text { cartilage }\end{array}$ & $\begin{array}{l}\text { Minor osteochondral injury } \\
\text { Osteochondral or chondral } \\
\text { fractures }\end{array}$ & $\begin{array}{l}\text { Chondropathy } \\
\text { (e.g. chondromalacia, } \\
\text { softening, and fibrillation) }\end{array}$ \\
\hline Ligament & Sprain or tear (grades I-III) & Inflammation \\
\hline Bursa & Traumatic bursitis & Bursitis \\
\hline Bone & $\begin{array}{l}\text { Periosteal contusion } \\
\text { Fracture }\end{array}$ & $\begin{array}{l}\text { Periostitis } \\
\text { "Bone strain"/“stress } \\
\text { reaction"/stress fracture } \\
\text { Osteitis } \\
\text { Apophysitis }\end{array}$ \\
\hline Muscle & $\begin{array}{l}\text { Acute compartment } \\
\text { syndrome } \\
\text { Contusion } \\
\text { Cramp } \\
\text { Strain or tear (grades I-III) }\end{array}$ & $\begin{array}{l}\text { Delayed onset muscle } \\
\text { soreness } \\
\text { Chronic compartment } \\
\text { syndrome }\end{array}$ \\
\hline Tendon & Tear (complete or partial) & $\begin{array}{l}\text { Tendinopathy (includes } \\
\text { paratenonitis, tendinosis and } \\
\text { tendonitis) }\end{array}$ \\
\hline Nerve & Neuropraxia & $\begin{array}{l}\text { Minor nerve injury or irritation } \\
\text { Entrapment }\end{array}$ \\
\hline Skin & $\begin{array}{l}\text { Puncture wound } \\
\text { Abrasion } \\
\text { Laceration }\end{array}$ & $\begin{array}{l}\text { Callus } \\
\text { Blister }\end{array}$ \\
\hline
\end{tabular}

injuries varies. Any age group can be affected, but they are most common in elite athletes aged 20-29 years, and noncompetitive athletes aged $30-49$ years. ${ }^{4}$

Tendon injuries are among the most common overuse injuries. One needs to distinguish between paratenonitis, tendinosis and tendonitis. Paratenonitis refers to peritendinitis and tenosynovitis, e.g. De Quervain's tenosynovitis at the wrist. This is most likely to occur where a tendon rubs over a bony prominence, irritating the paratenon (sheath). ${ }^{5}$ Tendinosis shows collagen disarray and separation, but absence of inflammatory cells on histology, e.g. rotator cuff tendinosis and Achilles tendinosis. ${ }^{6}$ Tendonitis is inflammation of the tendon itself and is mostly associated with the inflammatory arthritides. $^{7}$

To assist with the understanding of the classification of sports injuries, Table I represents injuries that can present acutely, or from overuse in various anatomical structures.

\section{Clinical examination}

The importance of making an accurate, pathological diagnosis cannot be overemphasised. Far too often, sports injuries are given descriptive labels such as "swimmer's shoulder" or "tennis elbow". These terms do not represent diagnoses. ${ }^{4}$ To make a diagnosis, one needs to take a thorough history, and complete a physical examination and appropriate special investigations. ${ }^{8}$

\section{History}

History-taking remains the keystone of accurate diagnosis. In the majority of cases, it will provide the diagnosis. ${ }^{5}$ It is helpful for the clinician to be familiar with the demands of the given sport to better understand the connection between various training practices and overload to specific musculoskeletal structures. ${ }^{3}$ Some of the important factors that should be addressed in the history include circumstances of the injury, description of the symptoms, general athlete health, training history and related aspects, as well as previous treatment received. ${ }^{3,5}$

\section{Examination}

On examination of the injured area, inspection can reveal important changes, such as swelling, bruising and deformity, as well as splinting or guarding. ${ }^{3}$ The examination should be complete, but with the focus on the injured part. ${ }^{3,9}$ The time-honoured system to use for musculoskeletal examination (that is, look, feel, move and X-ray) still holds true. The only variation is that an $X$-ray is often not ideal, and other imaging modalities are frequently more useful. ${ }^{10}$ Important principles to include in the examination are:

- Develop a routine;

- Examine the uninvolved side where relevant;

- Attempt to reproduce the symptoms;

- Assess local tissues;

- Assess for referred pain;

- Biomechanical examination (postural inspection, alignment of lower extremities and gait). ${ }^{5}$

Inspection, active and passive range of motion, palpation and strength testing are all mandatory in the examination routine. Many injuries have special tests linked with specific diagnoses. Some of the common special tests used in sports medicine are listed in Table II.

\section{Special investigations}

Radiological investigation forms a critical component of diagnosing musculoskeletal injuries. However, it is very important to acknowledge that this is only an aid to diagnosis. Therefore, one should understand the test being ordered, know how soon changes can be detected by investigations (e.g. scaphoid fracture is only visible on $\mathrm{X}$-rays 10 days after injury) and only order investigations 
Table II: Description and interpretation of common special tests used in sports medicine (Adapted from Anderson, 2005) ${ }^{3}$

\begin{tabular}{|c|c|c|}
\hline Structure to be tested & Test name & Description and interpretation \\
\hline \multirow[t]{4}{*}{ Nerve } & Lasegue's sign & $\begin{array}{l}\text { Description: When patient is supine with hip flexed, extension of the knee with dorsiflexion of the ankle } \\
\text { causes pain or muscle spasm. } \\
\text { Interpretation: Indicates lumbar root or sciatic nerve irritation. }\end{array}$ \\
\hline & Quadrant testing & $\begin{array}{l}\text { Description: Patient actively moves spine in all quadrants. } \\
\text { Interpretation: Restricted motion or reproduction of pain can pinpoint injured structure. }\end{array}$ \\
\hline & Modified Romberg's sign & $\begin{array}{l}\text { Description: Patient stands on one foot with eyes open and then closed; positive if closing the eyes } \\
\text { increases the unsteadiness. } \\
\text { Interpretation: A positive sign indicates a loss of proprioceptive control. }\end{array}$ \\
\hline & Tinel's sign & $\begin{array}{l}\text { Description: Electric shock-like pains are experienced when the examiner taps lightly on a peripheral } \\
\text { nerve. } \\
\text { Interpretation: Indicates nerve irritability. }\end{array}$ \\
\hline Vascular & Adson's test & $\begin{array}{l}\text { Description: Patient is seated, with head extended and turned to the side of the lesion; with deep } \\
\text { inspiration there is diminution, or loss, of radial pulse on the affected side. } \\
\text { Interpretation: A test for vascular obstruction with thoracic outlet syndrome. }\end{array}$ \\
\hline \multirow[t]{2}{*}{ Joint stability } & Lachman test & $\begin{array}{l}\text { Description: Patient lying down; knee flexed } 30 \text { degrees; examiner stabilises femur and quickly pulls } \\
\text { forward on tibia, assessing motion and quality of stopping point. } \\
\text { Interpretation: Increased motion or indistinct end point indicates anterior collateral ligament sprain. }\end{array}$ \\
\hline & McMurray's test & $\begin{array}{l}\text { Description: Rotation of tibia on femur while fully flexing and extending knee. } \\
\text { Interpretation: Restricted motion, a click, pop or locking indicates meniscus tear. }\end{array}$ \\
\hline Connective tissue & Ober's test & $\begin{array}{l}\text { Description: Patient lies on side with examiner holding hip abducted and extended. The abducted thigh } \\
\text { is then relaxed and allowed to drop into adduction. } \\
\text { Interpretation: Indicates a tight iliotibial band if the thigh does not fall into adduction; risk factor to } \\
\text { develop iliotibial band friction syndrome. }\end{array}$ \\
\hline
\end{tabular}

that will influence the management of the injury. One should also be able to interpret the investigation and explain the results to the patient. Poor quality imaging should not be accepted by a physician. ${ }^{3,11}$ One of the most exciting areas of change and progress in diagnosis and treatment in sports injuries includes the expanding use of imaging with magnetic resonance imaging (MRI) and musculoskeletal ultrasound (US). ${ }^{2,11}$

MRI has been described as the "most versatile and robust of all radiographic methods for examining injured athletes". 2,11 In MRI, a series of radiofrequency pulses are applied to the tissue, which causes the protons to change their alignment relative to the external magnetic field. The energy released during this realignment of protons is used to create the image. ${ }^{5}$ It has been suggested that positional MRI is more sensitive and specific than traditional MRI for viewing disorders such as spondylolysis, spondylolisthesis, or disc herniation, due to the fact that the signs and symptoms of low back pain may be postural-related and because anatomical structures change in position. Therefore, it may be useful to obtain MRIs in the flexed and extended position. ${ }^{2,11}$

Musculoskeletal US is a newer diagnostic tool that is changing the approach to diagnosis and treatment. There is a growing list of conditions for which US examination is becoming the preferred imaging technique. Furthermore, musculoskeletal US can be used for diagnosing dynamic conditions (such as tendon subluxations or shoulder impingement) because structures can be visualised during provocative dynamic manoeuvres. US can also be used to guide injections for treatment. It is important to bear in mind that it does not show the full extent of the pathological changes, and a skilled, experienced examiner is required. ${ }^{3,4,11}$

Electrodiagnostic studies, such as electromyography (EMG) and nerve conduction velocity, are used to evaluate radiculopathy and peripheral nerve entrapment. ${ }^{2,3,5}$ Muscle recruitment and co-activation of synergistic muscle groups can be determined by means of surface EMG. This can be helpful in teaching the athlete to use the appropriate muscle correctly. ${ }^{12,13}$

Intracompartmental pressures can be measured at rest, and during exercise, by means of a transducer placed within the muscle compartment, and may be indicated for acute injuries such as fractures, and with overuse injuries, such as exertional compartment syndrome. ${ }^{3,5}$

Occasionally a laboratory test is necessary to correctly diagnose the cause of a sports injury. Blood chemistry, haematology, urinalysis, joint fluid analysis, or bacterial cultures can be helpful when infectious or rheumatologic disorders are suspected. Laboratory tests may also be utilised to evaluate metabolic or hormonal abnormalities that may contribute to injury in patients suffering from diabetes mellitus, osteoporosis, and other metabolic diseases. ${ }^{3}$ 
Table III: Indications for special investigations for the evaluation of sports injuries ${ }^{2,3}$

\begin{tabular}{l|l|l|}
\hline Modality & When to request & Disadvantage \\
\hline $\begin{array}{l}\text { X-rays } \\
\text { Musculoskeletal ultrasound }\end{array}$ & $\begin{array}{l}\text { Bony abnormalities (fracture, growth plates) } \\
\text { Radioisotope bone scan (scintigram) }\end{array}$ & $\begin{array}{l}\text { Limited information on soft tissue and subtle } \\
\text { bone abnormality e.g. stress fracture }\end{array}$ \\
\hline $\begin{array}{l}\text { Detection of increased blood flow (inflammation and infection) and } \\
\text { bone turnover (stress fractures and tumours) }\end{array}$ & $\begin{array}{l}\text { Operator dependant } \\
\text { Sensitive, but non-specific }\end{array}$ \\
\hline $\begin{array}{l}\text { Magnetic resonance imaging } \pm \\
\text { arthrogram }\end{array}$ & bones; spine evaluation & Cost \\
\hline Conduction stion of subtle soft tissue changes and occult bony lesions & Cost \\
\hline Compartment pressure & Peripheral nerve abnormality & Patient discomfort \\
\hline
\end{tabular}

The decision to utilise diagnostic imaging, or any other special investigation, should be determined by the clinical suspicions, knowledge of the strengths and limitations of various special investigations, communication with the radiologist or relevant specialist, clinical correlation of the findings, questioning if there is a more cost-effective way to reach the diagnosis, and whether the results are going to change management. ${ }^{3}$ Table III summarises the commonly used special investigations or imaging techniques for sports injury evaluation.

\section{Management}

For effective treatment, one should establish a diagnosis and distinguish between an acute and an overuse injury. Treatment of an acute injury will be determined by the effects of the injury - torn, broken, deformed or displaced structures will need restoration of integrity, strength and realignment. An overuse injury's treatment, on the other hand, will be determined by the causes of the injury. Causes may be intrinsic or extrinsic in nature. Important intrinsic (body-related) factors are malalignments, leg-length discrepancy, muscle imbalance, inadequate strength, poor flexibility and neuromuscular coordination. Extrinsic factors include training errors and inappropriate training surfaces, technique and equipment. Symptomatic treatment alone will not resolve an overuse injury, e.g. unsuitable footwear could lead to recurrence of iliotibial band friction syndrome. . $^{3,4}$

Understanding the physiology of healing is important to successful treatment of acute sports injuries. In the first 72 hours there will be an influx of inflammatory cells that release biologically active substances (causing redness, swelling and pain) and start removing damaged tissue. This is called the inflammatory phase, and is followed by the repair or regenerative phase, lasting from 48 hours to 6 weeks. In this phase, one gets synthesis and deposition of type III collagen. The last phase is the remodelling phase which starts approximately 6 weeks after the injury, but can last up to 12 months. The remodelling phase is divided into a consolidation phase (type I collagen synthesis and alignment; commencing at about 6 weeks and continuing to approximately 10 weeks) and a maturation stage (fibrous tissue gradually changing to scar tissue). ${ }^{5,12-14}$ It is important to bear in mind that the healing process is unique in each patient and different tissues vary in their ability to regenerate..$^{5,14-16}$

Important goals in sports injury management should include the following:

- Minimisation of initial damage;

- Reduction of associated pain and inflammation;

- Promotion of healing of damaged tissue;

- Maintainence or restoration of flexibility, strength, proprioception and overall fitness (physiotherapy/ biokinetics);

- Functional rehabilitation to allow for successful return to sport;

- Assessment and correction of any predisposing factors.

\section{Initial treatment of injury}

Goals of initial management should comprise control of pain, reduction of swelling and redness, allowing optimum healing and facilitating patient rehabilitation. The "gold standard" of initial treatment of sports injuries follows the mnemonic RICE (relative rest, ice, compression and elevation). There are variations which one may also see in the sports injury literature, but they essentially contain the same elements. Despite general acceptance of this management process, there is a lack of evidence providing clinical details regarding duration, type and efficacy of methods utilised. , $^{4,17}$ 
Relative rest or "pain limited" exercise is now advocated for most injuries to prevent adverse joint stiffness, as well as muscle atrophy and weakness. Complete immobilisation is primarily required for acute fractures. ${ }^{4,5,17}$ Protected mobilisation refers to taping or bracing an injured structure to prevent movement in a direction that will cause further damage, but allows movement of uninjured structures. ${ }^{18}$ Taping is widely used in the field of rehabilitation, as both a means of treatment and prevention of sports-related injuries. Taping can be used to restrict undesired, potentially harmful motion and allow desired motion. Kinesiotaping is a taping method using a highly elastic and unique adhesive tape called Kinesio $\mathrm{Tex}^{\circledR}$. It is proposed that the application of this tape gives muscle support during activity, without affecting circulation or range of motion. ${ }^{4,5,18}$

\section{Pharmacological treatment}

Therapeutic drugs commonly used to manage pain and inflammation in the treatment of sports injuries include analgesics, nonsteroidal anti-inflammatory drugs (NSAIDs), corticosteroids and novel therapies such as prolotherapy, sclerotherapy, topical glyceryl trinitrate (GTN) and plateletrich plasma (PRP) injections.

- Analgesics: Analgesics are used in the acute phase, immediately after injury, to reduce pain. Subsequent use depends on the degree and duration of pain. ${ }^{5}$ Although not used by many people as first-line treatment, they have been shown to have similar efficacy to NSAIDs. ${ }^{10}$ The side-effect profile is also more favourable. Paracetamol at 3-4 $\mathrm{g}$ per day can be used in the acute phase of injuries. Topical analgesics are used extensively by athletes and are known as "sports rubs". Most commercially available topical analgesics contain a combination of substances such as menthol, methylsalicylate, camphor and eucalyptus oil. ${ }^{5}$

- NSAIDs: Debate around using these drugs is still ongoing. ${ }^{19}$ The latest recommendation is that inflammatory conditions, such as bursitis or synovitis, and impingement syndromes, warrant short-term treatment with NSAIDs, but that it can be detrimental in non-inflammatory conditions. Side-effects such as gastritis should be kept in mind. ${ }^{20,21}$ COX-2 (cyclooxygenase) inhibitors may be a safer option. ${ }^{17} \mathrm{~A}$ number of topical anti-inflammatory products are available. Topical agents are useful in soft tissue injuries because they are delivered non-invasively in a localised area. More recently, anti-inflammatory drugs have been applied through a patch which releases the drug over 24 hours. 5,15
- Corticosteroids: Corticosteroids can be administered orally, ${ }^{22}$ by local infiltration or by iontophoresis. ${ }^{21}$ Their use is controversial and in high-level athletes, a therapeutic use exemption or declaration of use may be required by anti-doping regulatory bodies, depending on the route of administration. ${ }^{23}$ Corticosteroids can initially be used, while the causative problem is being addressed ,e.g. injecting a tennis elbow for symptomatic relief, but at the same time evaluating the grip of the tennis racquet, and adding a decompression brace. ${ }^{23-26}$

- Newer therapeutic options include the use of prolotherapy (injecting multiple sites on a painful ligament or tendon insertion with $10 \%$ dextrose, phenol-glycerine-glucose or sodium morrhuate), ${ }^{27}$ sclerotherapy (polidocanol injection; traditionally used for varicose veins), ${ }^{28,29}$ topical $G T N^{30-33}$ and injecting $P R P P^{34-38}$ Novel therapies still lack evidence through high-quality, randomised controlled trials, but show promise. The use of prolotherapy dates to the 1930s when it was developed for pain associated with presumed ligament laxity. ${ }^{38} \mathrm{~A}$ small volume of an irritant solution is injected at multiple sites. The volume depends on the region of injection. ${ }^{5}$ Prolotherapy may have value in the treatment of chronic enthesopathies, tendinopathies, and osteoarthritis. Continued research into prolotherapy is required to determine what specific agents and protocols are needed to successfully treat patients with this modality. ${ }^{2}$ Research regarding the use of sclerotherapy for the treatment of sports injuries is very limited. In a recent pilot study conducted by Alfredson and Ohberg, it was concluded that injections with the sclerosing substance, polidocanol, have the potential to reduce tendon pain during activity in patients with chronic painful mid-portion Achilles tendinopathy. ${ }^{29}$ Studies on topical administration of GTN have provided conflicting results. ${ }^{2}$ However, the results of some studies indicate that it may be effective in the treatment of chronic tendinopathies. ${ }^{31-33}$ Through the use of GTN, nitric oxide may fuel collagen synthesis and it is hypothesised that the reduction in pain is as a result of the collagen synthesis. ${ }^{31-33,39}$ Recently, there has been a significant interest in the use of PRP to enhance healing. ${ }^{37}$ PRP is prepared from autologous whole blood, which is centrifuged to concentrate platelets in plasma. Platelets contain at least six growth factors vital to bone and soft-tissue healing. ${ }^{38}$ Preliminary results are promising in terms of earlier return to competition after muscle and particularly tendon injury. ${ }^{2}$ 


\section{Therapeutic modalities}

Physiotherapists and those in the related field routinely incorporate the use of therapeutic modalities for the treatment of sports injuries. There is a wide array of therapeutic options available, including massage, cryotherapy, contrast baths, ultrasound, electrotherapy, laser, acupuncture and dry needling. Unfortunately, there is still a lack of conclusive scientific evidence in favour of these modalities, but anecdotal evidence shows that these modalities may be beneficial for the treatment of sports injuries. ${ }^{40-50}$ Selection of the appropriate modality should be based on an accurate clinical diagnosis of the injury and a decision about which modality can most effectively reach the desired target tissue to achieve specific results. ${ }^{51}$

\section{Surgery}

Despite the many advances in the non-operative management of sports injuries and the fact that conservative treatment is always favoured, surgery has a major role to play in the management of acute and overuse injuries. ${ }^{5}$ Surgery aims to realign, reconstruct or repair damaged tissue. ${ }^{52,53}$ Depending on the type of injury, immediate or postponed referral may be indicated, for example Achilles tendinopathy should first be treated conservatively and only be referred for surgery if these methods fail, while immediate referral for a knee dislocation is imperative.

Postsurgical rehabilitation is also a critical component in the process and should be considered to be equally important as the procedure itself. 4,5

\section{Return to play and prevention of re-injury}

Return to play is always a contentious matter as most athletes want to start training as soon as possible, and in the professional arena, loss of earnings is a problem. Unfortunately, premature clearance to return to play carries the risk of delayed healing or further injury.

A definite time frame is difficult to provide, as different sports demand variable recovery rates. ${ }^{3}$ Furthermore, all exercise rehabilitation plans must determine what is meant by complete recovery from an injury. Often it means that the athlete is fully reconditioned once he or she has achieved full range of movement, strength, neuromuscular control, cardiorespiratory fitness, and sport-specific functional skills. In addition, besides physical well-being, the athlete must also have regained full confidence to return to his or her sport. ${ }^{54}$

Finally, prevention is always better than cure. Factors that may assist in preventing injury or re-injury include warm up, stretching, taping/bracing, protective equipment, suitable sports equipment/gear, appropriate training surfaces, appropriate training programme, adequate recovery and correction of biomechanical deviations or faulty technique.

\section{Conclusion}

The term "sports injuries" is very broad, encompassing a wide variety of anatomical structures. It is essential to make a correct diagnosis as the outcome will depend on proper, focused treatment. Therefore, one should have an allinclusive approach to diagnoses, and a management plan that strives to do no harm, but still achieve return to play as soon as possible.

\section{Acknowledgement}

To Mrs Brenda Weder for her contribution in preparing the manuscript.

\section{References}

1. Prentice WE. Fitness for college and life. $4^{\text {th }}$ ed. Missouri: Mosby; 1994.

2. Borg-Stein J, Zaremski JL, Hanford MA. New concepts in the assessment and treatment of regional musculoskeletal pain and sports injury. Am J Phys Med Rehabil. 2009;1:744-754.

3. Anderson SJ. Sports injuries. Dis Mon. 2005;438-542.

4. Peterson L, Renström P. Sports injuries: their prevention and treatment. $3^{\text {rd }}$ ed. Human Kinetics, Champaign; 2001;1-61.

5. Brukner P, Khan K. Clinical sports medicine. $3^{\text {rd }}$ edition (revised), Australia: McGraw Hill Medical; 2009; 8-157.

6. Khan KM, Cook JL, Bonar F, et al. Histopathology of common overuse tendon conditions: update and implications for clinical management. Sports Med. 1999;27:393-408.

7. Krishna Sayana M, Maffulli N. Insertional achilles tendinopathy. Foot Ankle Clin. 2005;10:309-20.

8. Khan KM, Tress BN, Hare WS, Wark, JD. Treat the patient, not the $\mathrm{X}$-ray: advances in diagnostic imaging do not replace the need for clinical interpretation. Clin J Sport Med. 1998;8:1-4.

9. Plastaras CT, Rittenberg JD, Rittenberg, et al. Comprehensive functional evaluation of the injured runner. Phys Med Rehabil Clin North Am. 2005;16:623-649.

10. Sloan J. Soft tissue injuries: introduction and basic principles. Emerg Med J. 2008;25:33-37.

11. Sanders TG, Fults-Ganey C. Imaging of sports-related injuries. De Lee JC, Drez D Jr, eds. Orthopaedic Sports Medicine. 2nd edition. Philadelphia: Saunders Elsevier Science; 2003.

12. Cam JR, Chriswell E. Introduction to surface electromyography. Sudbury: Jones \& Bartlett Publisherd; 2011;141-158.

13. Floyd RT. Manual of structural kinesiology. $17^{\text {th }}$ ed. Boston: McGraw Hill; 2009;46-47.

14. Sharma $P$, Maffuli N. Basic biology of tendon injury and healing. Surgeon. 2005;3(5):309-316.

15. Wong ME, Hollinger JO, Pinero GJ. Integrated process responsible for soft tissue healing. Oral Surg, Oral Med, Oral Pathol, Oral Rdiol Endod. 1996;82(5):475-492.

16. Barlow Y, Willoughby J. Pathophysiology of soft tissue repair. $\mathrm{Br}$ Med J. 1992;48(3):698-711. 
17. Smith M. A review of the initial management of soft tissue sports injuries. Journal of Orthopaedic Nursing. 2005;9:103-107.

18. Thelen MD, Dauber JA, Stoneman PD. The clinical efficacy of kinesio tape for shoulder pain: a randomised, double-blinded, clinical trial. J Orthop Sports Phys Ther. 2008;38(7):389-395.

19. Mehallo CJ, Drezner JA, Bytomoski JR. Practical management: nonsteroidal antiinflammatory drug (NSAID) use in athletic injuries. Clin J Sport Med. 2006;16;170-174

20. Warden SJ. Prophylactic misuse and recommended use of nonsteroidal anti-inflammatory drugs by athletes. $\mathrm{Br} J$ Sports Med. 2009;43:548-549.

21. Hertel J. The role of nonsteroidal anti-inflammatory drugs in the treatment of acute soft tissue injuries. J Athl Train. 1997;32(4):350-358

22. Harmon KG, Hawley C. Physician prescribing patterns of oral corticosteroids for musculoskeletal injuries. J Am Board Fam Pract. 2003;16:209-212.

23. Nichols AW. Complications associated with the use of corticosteroids in the treatment of athletic injuries. Clin J Sport Med. 2005;15:370-375.

24. Drug Free Sport SA. Prohibited substance list based on the World Anti-Doping Code 2010.

25. Charalambous C, Paschalides C, Sadiq S, et al. Weight bearing following intra-articular steroid injection of the knee: survey of current practice and review of the available evidence. Rheumatol Int. 2002;22(5):185-7.

26. Dvorak J, Feddemann N, Grimm K. Glucocorticosteroids in football: use and misuse. $\mathrm{Br} J$ Sports Med. 2006;40 Suppl1:i48-54.

27. Rabago D, Best TM, Beamsley M, Patterson J. A systematic review of prolotherapy for chronic musculoskeletal pain. Clin $J$ Sport Med. 2005;15(5):E376.

28. Ohberg L, Alfredson H. Ultrasound guided sclerosis of neovessels in painful chronic Achilles tendinosis: pilot study of a new treatment. Br J Sports Med. 2002;36(3):173-177.

29. Alfredson H, Ohberg L. Sclerosing injections to areas of neovascularisation reduce pain in chronic Achilles tendinopathy: a double-blind randomised controlled trial. Knee Surg Sports Traumatol Arthrosc. 2005;13(4):338-344.

30. Berrazueta JR, Losada A, Poveda J, et al. Successful treatment of shoulder pain syndrome due to supraspinatus tendinitis with transdermal nitroglycerin. A double blind study. Pain. 1996;66(1):63-67.

31. Murrell GA. Topical glyceryl trinitrate treatment of chronic noninsertional Achilles tendinopathy. A randomised doubleblind placebo-controlled trial. $J$ Bone Joint Surg Am. 2004;86A(5):916-922.

32. Paoloni JA, Appleyard RC, Nelson J, Murrell GA. Topical nitric oxide application in the treatment of chronic extensor tendinosis at the elbow: a randomised, double-blinded, placebo-controlled clinical trial. Am J Sports Med. 2003;31(6):915-920.

33. Paoloni JA, Appleyard RC, Nelson J, Murrell GA. Topical glyceryl trinitrate application in the treatment of chronic supraspinatus tendinopathy: a randomised, double-blinded, placebocontrolled clinical trial. Am J Sports Med. 2005;33(6):806-813.

34. Foster TE, Puskas BL, Mandelbaum BR, et al. Platelet-rich plasma. From basic science to clinical applications. Am J Sports Med. 2009;37(11):2259-2272.

35. Mei-Dan G, Mann G, Maffulli N. Platelet-rich plasma: any substance into it. Br J Sports Med. 2010;44:618-619.

36. Fullerton $\mathrm{BD}$, Reeves $\mathrm{KD}$. Ultrsonography in regenerative injection (prolotherapy) using dextrose, platelet-rich plasma, and other injectants. Phys Med Rehabil Clin N Am. 2010; 21:585-605
37. Harmon KG. Muscle injuries and PRP: what does the science say? Br J Sports Med. 2010; 44(9):616-617.

38. Rabago D, Best TM, Zgierska, et al. A systematic review of four injection therapies for lateral epicondylosis: prolotherapy, polidocanol, whole blood and platelet-rich plasma. Br J Sports Med. 2009; 43:471-481.

39. Schäffer MR, Efron PA, Thornton FJ, et al. Nitric oxide, an autocrine regulator of wound synthetic function. J Immunol. 1997; 158:2375-2381.

40. Green S, Buchbinder R, Glazier R, Forbes A. Systematic review of randomised controlled trials of interventions for the painful shoulder: selection criteria, outcome assessment, and efficacy. BMJ. 1998;316:354-360

41. Khadilkar A, Milne S, Brosseau L, et al. Transcutaneous electrical nerve stimulation (TENS) for chronic low-back pain. Spine 2005;30(23):2657-2666.

42. Bjordal JM, Couppe C, Chow RT, et al. A systematic review of low level laser therapy with location-specific doses for pain from chronic joint disorder. Aust J Physiother. 2003;49(2):107-116.

43. Hoving JL, Koes BW, de Vet HC, et al. Manual therapy, physical therapy, or continued care by a general practitioner for patients with neck pain. A randomised, controlled trial. Ann Intern Med. 2002;136(10):713-722.

44. Jull $\mathrm{G}$, Trott $\mathrm{P}$, Potter $\mathrm{H}$, et al. A randomised controlled trial of exercise and manipulative therapy for cervicogenic headache. Spine. 2002;27(17):1835-1843.

45. Gerwin RD, Shannon S, Hong CZ, et al. Interrater reliability in myofascial trigger point examination. Pain. 1997;69(1-2):65-73.

46. Lucas KR, Polus BI, Rich PA. Latent myofascial trigger points: their effects on muscle activation and movement efficiency. $J$ Bodywork Movement Ther. 2004;8:160-166.

47. Huguenin LK. Myofascial trigger points: the current evidence. Phys Ther Sport. 2004;5:2-12.

48. Garvey TA, Marks MR, Wiesel SW. A prospective, randomised, double-blind evaluation of trigger-point injection therapy for low-back pain. Spine. 1989;14(9):962-964.

49. Hong CZ. Lidocaine injection versus dry needling to myofascia trigger point. The importance of the local twitch response. Am Phys Med Rehabil. 1994;73(4):256-263.

50. Madsen MV, Gøtzsche PC, Hróbjartsson A. Acupuncture treatment for pain: systematic review of randomised clinical trials with acupuncture, placebo acupuncture, and no acupuncture groups. BMJ. 2009;338:a3115.

51. Prentice WE. Principles of athletic training: A competencybased approach. 14 ${ }^{\text {th }}$ ed. New York: McGraw Hill; 2011;379.

52. Fink C, Hoser C, Hackl W, Ravarro RA, Benedetto KP. Long-term outcome of operative or non-operative treatment of anterior cruciate ligament rupture: is sports activity a determining variable? Int J Sports Med. 2001;22:304-309.

53. Fithian DC, Paxton EW, Stone ML, et al. Prospective trial of a treatment algorithm for the management of the anterior cruciate ligament injured knee. Am J Sports Med. 2005;33(3):335-346.

54. Prentice WE. Essentials of athletic injury management. $8^{\text {th }}$ ed. New York: McGraw Hill; 2010;297. 